\title{
Goldberg-en Antsietate eta Depresio Eskala: euskarazko egokitzapenaren ikerketa pilotua
}

\author{
Joanes Lameirinhas Ortuoste eta Arantxa Gorostiaga Manterola \\ EHUko Psikologia Fakultatea
}

\begin{abstract}
Euskarara egokitutako eta baliozkotutako ebaluazio-tresnak garatzeak behar bat izaten jarraitzen du. Egun ez dago adineko pertsonen dimentsio emozionalaren ebaluazioa egiteko aukera ematen duen euskarazko galde-sortarik. Behar horri erantzuteko, lan honetan, Escala de Ansiedad y Depresión de Goldberg (EADG) galde-sorta euskarara egokitzeko ikerketa pilotua gauzatu da. Guztira Nafarroako eta Gipuzkoako eremu soziolinguistiko ezberdinetako 68 adineko pertsona egoitzaratuk parte hartu dute, euskal hiztunak direnak, eta EADGaren euskarazko bertsioa (GADE) pasa zaie. Hasierako emaitzek adierazi dute euskarazko bertsioak barnetrinkotasun egokia duela. Era berean, hitz batzuek zalantza bat edo beste eragin duten arren, parte-hartzaileek, orokorrean, itemekiko ulermen egokia azaldu dute. Hartara, emaitzek iradokitzen dute GADEa, egokitzapenaren fase esperimentalari begira, tresna fidagarria izan daitekeela antsietatearen eta depresioaren baheketa egiteko adineko euskal hiztun egoitzaratuekin.
\end{abstract}

GAKO-HITZAK: Testen egokitzapena · Depresioa · Antsietatea · Adineko pertsonak.

\section{Goldberg Anxiety and Depression Scale: Pilot study of the Basque adaptation}

Developing Basque-adapted and validated assessment tools is still an unsolved need. Nowadays, there is no Basque questionnaire to assess the emotional dimension of elderly people. In order to respond to this need, in this work, a pilot research was realised to adapt the Spanish version of Goldberg Anxiety and Depression Scale (GADS) to Basque. Participants were 68 Basque-speaking institutionalised elders from different sociolinguistic areas in Navarre and Gipuzkoa that answered the Basque version of GADS (GADE). Preliminary results have shown that the Basque version has an adequate internal consistency. Despite some doubts in specific words, the results indicate a generally good items' understanding from the subjects. Thus, the results of this pilot research suggest that GADE, regarding the experimental phase of adaptation, seems to be a reliable tool in order to assess anxiety and depression in Basque institutionalised elderly people.

KEY WORDS: Test adaptation - Depression · Anxiety · Elderly people. 


\section{Nondik norakoak}

Azken urteotan zahartzaroarekiko eta adineko pertsonekiko interesa areagotu egin da, etorkizun hurbilean aurreikusten diren aldaketa soziodemografikoak direla-eta. Medikuntzan suertatu diren aurrerapenen eta bizi-kalitatean jazo diren hobekuntzen ondorioz, heriotza-tasa txikiagotu eta bizi-itxaropena handitu egin dira. Egoera horrek bat egin du gizarte-aldaketa anitzen ondorioz behera egin duen jaiotza-tasarekin, biztanleria-piramidearen alderantzikatzeari bide emanez (Agulló, 2001). Hala, 65 urtetik gorakoen proportzioak, biztanleriako beste segmentuekin alderatuta, gora egingo du hurrengo urteotan. Fenomeno honi «biztanleriaren zahartze» deritzo (Vinuesa eta Moreno, 2000).

Osasunaren Munduko Erakundeak (OME, 2015), 2050. urterako, 60 urtetik gorakoen populazioa bikoiztu egingo dela adierazi du. Euskal Herriko estatistikainstitutu ezberdinek ere joera gorakor horren berri ematen dute. Euskal Autonomia Erkidegoan, 2000. urtean, 65 urtetik gorako pertsonak biztanleria osoaren $\% 17$ ziren. Gaur egun, ehuneko hori \% 22,2an zehazten da, eta 2031. urteari begira, $\%$ 28,2ra iritsiko da. Berebat, 80 urtetik gorakoen populazioa bikoiztu egin da mende-hasieratik (\% 3,6tik \% 7,3ra; \% 111ko areagotzea), eta $2031 \mathrm{n}$ populazio osoaren \% 9,5 izatea aurreikusten da (Euskal Estatistika Erakundea [EUSTAT], 2017). Nafarroan, 2018tik 2022ra adineko pertsonen ehunekoa \% 19,5etik \% 20ra igotzea espero da (Nafarroako Estatistika Erakundea [NASTAT], 2019; Nafarroako Gobernua, 2017). Euskal Herrian, 2030era begira, 65 urtetik gorakoen biztanleria herena handituko da, 14 urtetik beherakoena laurdena baino gehiago murriztuko den bitartean (Gaindegia, 2015).

Datu horiek populazioaren zahartzea gertatzen ari dela mahaigaineratzen dute. Adineko pertsonen taldea modu esanguratsuan hazten ari da, eta gero eta gehiago dira adin aurreratuenetara iristen direnak (Abellán et al., 2019). Hau da, pertsona nagusiak gero eta gehiago dira, eta zaharragoak izatera heltzen dira. Errealitate honek askotariko ondorioak ekarriko ditu arlo ekonomiko, politiko, sozial eta kulturalean, eta ondorio horiei aurre egiteko gizartea baliabidez hornitzeko beharra agerian jartzen du.

Gaur egun, gizarte ororen erronka handienetako bat adineko pertsonek etorkizun hurbil zein urrunean beharko dituzten zaintza eta premiei aurre egitean datza, zahartzeak ekar ditzakeen ondorio guztiak direla-eta. Horrek berebiziko garrantzia hartzen du osasunaren alorrean; izan ere, zahartzen goazen heinean, gaixotasun eta nahasmendu kronikoekiko zaurgarritasuna areagotu egiten da (OME, 2015), eta ondorioz, zenbait jarduera egiteko zailtasunak sor edota ezgaitasuna gara litezke (Calvo-Soto eta Gómez-Ramírez, 2018; OME, 2011). Halaber, adinarekin, gaitasun kognitiboen narriadura jazotzeko arriskua handitu egiten dela aurkitu da (ÁlvarezHernández eta Sicilia, 2007; López eta Calero, 2009).

Zahartzaroaren inguruko egungo hizpide nagusiak zahartzaro aktibo eta osasuntsuaren sustapena eta gaixotasunen prebentzioa diren arren, tradizionalki, populazio horren nahasmendu kognitibo eta emozionalak izan dira ikergai. Hau ez 
da harritzekoa, hirugarren adinekoengan nahasmendu horiek duten prebalentzia aintzat hartuta.

Nahasmendu emozionalei dagokienez, depresioa eta antsietatea dira, hain zuzen, zahartzaroan ohikoenak direnak (Andreas et al., 2017). Gehien ikertutakoa depresioa izan da, eta nahasmendu horren inguruko datu epidemiologikoek aldakortasun handia azaltzen dute. Gallagher eta Thompson-en (1983) ekarpen klasikoaz geroztik, adineko pertsonen \% 7-11k nahasmendu depresiboren bat pairatzen duela uste izan da. Íñiguez-i (2009) jarraikiz, ordea, hizpide den adin-taldeko nahasmendu depresiboen prebalentzia \% 30-50 artean legoke. Azken hamarkadan Espainiako Estatuan egindako zenbait ikerketaren emaitzak ere tarte horretan kokatzen dira (adib., Damián, Pastor-Barriuso eta Valderrama-Gama, 2010; Sarró et al., 2013). Halaber, sintomatologia depresiboa aurkezten duten adineko pertsonen ehunekoa $\%$ 65era hel liteke (Molina-Linde et al., 2005).

Etiologiari begira, nahasmendu edo sintomatologia depresiboaren agerpena zenbait arrisku-faktorerekin lotu izan da adinekoetan, besteak beste: emakume izatea (Sendra, Asensio eta Vargas, 2017); banandu-, dibortziatu- edo alargun-egoera (Buber eta Engelhardt, 2011; Vink, Aartsen eta Schoevers, 2008); bakarrik bizitzea (Fernández-Fernández et al., 2006); babes sozial urria (Vink, Aartsen eta Schoevers, 2008); hezkuntza-maila baxua (Escobar et al., 2013); narriadura kognitiboa (Sarró et al., 2013); osasun-arazoak (Volkert et al., 2017); eta mendekotasuna (Yaka et al., 2014). Bestalde, zaharren egoitzetan instituzionalizatutako pertsonek, ezinstituzionalizatuekin alderatuta, sintoma depresibo gehiago aurkezten dituztela aurkitu da (Azeem eta Naz, 2015). Horrek bat egingo luke Franco eta Monfortek (1996) Espainiako Estatuan egindako ikerketa batean aurkitutako emaitzekin. Horien arabera, komunitatean bizi diren adinduen \% 10i eragingo lioke nahasmendu honek, baina egoitzetan bizi direnen kasuan, ehunekoak gora egingo luke, \% 15-35i eragingo liokeen heinean.

Antsietateari dagokionez, denboran zehar adostasun handia egon da adineko pertsonen \% 10-20k sintomatologia antsiosoa pairatzen duela baieztatzean (Sheikh, 1996); are gehiago, hainbat ikerketak tarte horretako ehunekoak aurkitu dituzte (adib., Andreas et al., 2016; Beekman et al., 2000; Montorio et al., 2001; Norton et al., 2012). Sintomatologia antsiosoaz landa, Cisneros eta Ausín-en (2019) arabera, antsietate-nahasmenduen prebalentzia \% 20,8koa litzateke lagin adierazgarriak eta ebaluazio-tresna egokiak erabiltzean.

Antsietate-nahasmendu zein -sintomak aurkeztea, tradizionalki, zenbait arriskufaktorerekin erlazionatu izan da; hala nola emakume izatea (Grenier et al., 2019), bakarrik bizitzea (Antón, Gálvez eta Esteban, 2006); sare sozial txikia (Beekman et al., 2000); hezkuntza-maila baxua (Lowe eta Reynolds, 2005); narriadura kognitiboa (Bryant, Jackson eta Ames, 2008), eta gaixotasun kronikoren bat pairatzea edo muga funtzionalak izatea (Antón, Gálvez eta Esteban, 2006; Beekman et al., 2000).

Halaber, depresioaren kasuan bezala, komunitatean bizi diren adineko pertsonek antsietatea pairatzeko probabilitate txikiagoa lukete. Horren harira, Bryant eta haren 
laguntzaileek (2008) komunitatean bizi ziren \% 1,2-15ek eta testuinguru klinikoko (zaharren egoitzak, ospitaleak...) \% 1-28k antsietate-nahasmenduren bat pairatzen zuela aurkitu zuten. Gainera, sintoma antsiosoak aurkezten zituztenak gehiago ziren: komunitatean bizi zirenen kasuan, \% 15-52,3k aurkezten zituen, eta lagin klinikoaren kasuan, \% 15-56k.

Askotan bere aldetik ikertuak izan diren arren, depresioa zein antsietatea hertsiki erlazionatuta aurkitu dira. Hala, azterlan ezberdinek adierazi dute depresioa dutenen $\%$ 17-57k antsietate-nahasmenduren bat azaltzen duela eta, alderantziz, antsietatea dutenen \% 13-28k aldibereko depresioa agertzen duela (Almeida et al., 2012; Beekman et al., 2000; Suradom et al., 2019; van Balkom et al., 2000). Komorbilitate hori dela-eta, nahasmendu zein sintoma depresibo eta antsiosoak ezberdintzeko gai diren neurriak garatzea garrantzitsua litzateke.

Adierazi diren datuek nahasmendu emozionalek hirugarren adinekoengan duten prebalentziaren eta larritasunaren berri ematen dute. Haatik, azpimarratu nahi da adineko pertsonek nahasmendu emozionalak beste adin-taldeek baino maila handiagoan azaltzen dituztela pentsa badaiteke ere, ikerketek ez dutela adinaren eta psikopatologia garatzearen arteko harremanaren inguruan ondorio argirik atera (Blazer et al., 1991; Buber eta Engelhardt, 2011; Stordal, Mykletun eta Dahl, 2003; Wild et al., 2012). Are gehiago, onartu izan da adina ez dagoela psikopatologiarekin modu zuzenean erlazionatuta (adib., Montorio et al., 2001). Dena dela, adinarekin batera nahasmendu emozionalak pairatzeko arrisku-faktoreak gehitu egiten dira, eta, horiek, psikopatologiaren agerpena erraz lezakete (Stordal et al., 2001).

Arestian esandako guztia aintzat hartuta, depresioaren eta antsietatearen ebaluazioa baliagarria suertatu da, batik bat, klinika-alorrean; izan ere, orientabide egoki eta doiak eskaintzea baimentzen du prebentzioari eta tratamenduari dagokienez. Horrek berebiziko garrantzia hartzen du adinduen populazioa areagotzen ari den egungo gizartean, non litekeena den antsietatea eta depresioa populazio horretan hedatutako osasun-arazo bihurtzea (Franco eta Monforte, 1996; Wolitzky-Taylor et al., 2010).

Haatik, alor klinikoan, dimentsio kognitiboaren ebaluazioa gailendu izan da. Edozein adin-taldetan funtzio kognitiboak ebaluatzeko tradizionalki erabili izan den tresna Mini-Mental State Examination (MMSE; Folstein, Folstein eta McHugh, 1975) da, baheketa edo screening gisa erabiltzen dena; hau da, funtzio kognitibo ezberdinen azaleko ebaluazioa egiteko aukera ematen du, aplikazio azkar eta erraz baten bitartez. Gaztelaniara eta espainiar kulturara egokitutako bertsioa ere badago, Mini-Examen Cognoscitivo deitua (MEC; Lobo et al., 1979). Bestalde, funtzio kognitibo bakoitzaren ebaluazio sakonagoa egiteko probak ere badaude; besteak beste, Wechler Memory Scale (WMS; Wechler, 1987) eta Rey-Osterrieth Complex Figure (ROCF; Rey, 1941; Osterrieth, 1944).

Dimentsio kognitiboa aztertzen duten tresnen garapen emankorraren kontrara, dimentsio emozionala neurtzen duten tresnek ez dute bilakaera handirik izan adinduen populazioan (Íñiguez, 2009). Hutsune horrek talka egiten du aurrez azaldutako errealitatearekin; izan ere, aurkeztutako prebalentziek argi adierazten 
dute depresio- eta antsietate-mailak handi samarrak direla hirugarren adinekoen populazioan.

Nahasmendu emozionalak ebaluatzeko teknikarik eraginkorrena elkarrizketa klinikoa den arren, elkarrizketatzaileak trebetasun jakin batzuk izatea eskatzen du, eta hortaz, teknika hori zenbait galde-sortaz osatzeak psikopatologiaren detekzioa erraz eta hobe lezake (Fernández-Alonso et al., 2007). Galde-sorta horiek autotxostenak izan ohi dira, eta haien erabilera oso zabalduta dago (Leturia et al., 2001; Montorio, 1994).

Depresioaren kasuan, adineko pertsonekin erabilienak diren autotxostenak hauek dira: Beck Depression Inventory (BDI; Beck et al., 1961), Zung Self-rating Depression Scale (SDS; Zung, 1965) eta Geriatric Depression Scale (GDS-30; Brink et al., 1982; Yesavage et al., 1983). Hala ere, azken tresna hori izan da, jatorriz, adineko pertsonen depresioa neurtzeko sortutako tresna bakarra.

Antsietatearen neurketari dagokionez, adineko pertsonentzat espezifikoak diren autotxostenak Geriatric Anxiety Inventory (GAl; Pachana et al., 2007) eta Geriatric Anxiety Scale (GAS; Segal et al., 2010) dira. Beck Antxiety Inventory (BAI; Beck et al., 1988) tresna ere aipatu behar da, adineko pertsonekin erabiltzeko sortua izan ez arren, populazio horren ebaluazioa egiteko baliatu izan dena.

Halaber, sintomatologia depresiboazeinantsiosoaneurtzendituztenautotxostenak ere badaude: Hospital Anxiety and Depression Scale (HADS; Zigmond eta Snaith, 1983) eta Goldberg Anxiety and Depression Scale (GADS; Goldberg et al., 1988). Jatorriz ez ziren adinekoen populazioa ebaluatzeko sortu, baina populazio horretara baliozkotuak izan dira. Biak ere baheketarako erabiltzen dira; hots, nahasmendu emozionalen bat ager dezaketen kasuak antzemateko diseinatuta daude, baina ez dute diagnostikatzeko balio. Aitzitik, lortutako emaitzek gerora ebaluazio sakonago baten beharra adieraz dezakete. Baheketa-tresnak oso baliagarriak suertatzen dira, batik bat, testuinguru instituzionalizatuetan, non baliabide pertsonalen gabeziak eta denbora-mugapenak nabarmenak diren.

Horrez gain, adineko pertsonekin jardutean, autotxostenak laburrak, ulertzeko eta erantzuteko errazak eta beren hezkuntza-mailara egokituak izan behar direla iradokitzen da (Montorio, 1994). Ildo horretatik, GADSaren erantzun guztiak dikotomikoak (bai/ez) direla aipatu behar da, HADSeko itemek lau erantzun posible dituzten bitartean, eta gainera, ezberdinak item bakoitzean. Horrela, GADSak adinekoaren erantzuna errazten $\mathrm{du}$, ez baita hainbat erantzunen artean aukeratu behar (HADSean gertatzen den bezala). Bestalde, GADSa elkarrizketa klinikoarekin batera pasatzeko sortua da, hartara, elkarrizketatuaren inguruko informazio baliagarria eskuratzea errazagoa izanik. Aitzitik, HADSa, berez, adineko pertsonek berek irakurtzeko eta betetzeko sortua da, eta horrek eragozpenak ekar litzake: batetik, subjektuak irakurtzeko edo/eta erantzuteko zailtasunak adieraz ditzakeelako; eta bestetik, elkarrizketa batean azalera daitekeen informazio baliagarria galtzen delako. Hala, GADSaren aplikazioa errazagoa eta erabilgarriagoa suerta liteke hizpide den populazioan. 
Beraz, GADSa, adineko pertsonen azaleko ebaluazio emozionala egiteko tresna egokia dela esan daiteke. Bi azpieskalaz osatuta dago: bata antsietateari dagokio, eta bestea depresioari. Azpieskala bakoitzak 9 item ditu, bakoitzak sintoma bati erreferentzia egiten diolarik, eta erantzun guztiak dikotomikoak (bai/ez) dira. Baiezko bakoitza puntu bat izango litzateke, eta puntuen baturatik, azkenean, azpieskala bakoitzeko puntuazio totala eratortzen da. Bi azpieskaletan, lehenengo lau itemek baheketa bideratzen dute. Hala, antsietatearen azpieskalan, ebaluatuak lehenengo 4 itemetan bi baiezko edo gehiago emanez gero, hurrengo 5 itemak planteatuko litzaizkioke; aitzitik, depresioaren azpieskalan, baiezko bakar bat nahikoa izango litzateke hurrengo 5 itemak planteatzeko. Antsietatearen azpieskalan ebaki-puntua 5ekoa da, eta depresioaren azpieskalan 2koa. Goldberg eta haren laguntzaileen (1988) arabera, ebaki-puntu horiek gainditzen dituztenek \% 50eko probabilitatea lukete nahasmendu emozionalen bat pairatzeko, eta zenbat eta puntuazio altuagoa izan, probabilitate hori handiagoa litzateke. Hortaz, kasu horietan, ebaluazio zehatzagoa egin beharko litzateke, balizko nahasmenduak hobeto neurtzeko xedearekin.

Ezaugarri psikometrikoei dagokienez, jatorrizko bertsioak \% 91ko sentsibilitatea eta \% 86ko espezifikotasuna azaldu ditu (Goldberg et al., 1988). GADSa gaztelaniara eta espainiar gizartera egokitua izan da, Escala de Ansiedad y Depresión de Goldberg (EADG) izenpean (Montón et al., 1993). Autore horiei jarraikiz, gaztelaniara egokitutako tresnak \% 83ko sentsibilitatea eta \% 82ko espezifikotasuna ditu, jatorrizko bertsioarenak baino baxuagoak, baina egokiak, hala eta guztiz ere. Gainera, testak $\%$ 95,3ko balio aurresale positiboa duela aurkitu zuten. Aipa bedi gaztelaniazko galde-sortan ebaki-puntuak ezberdinak direla: antsietatearen azpieskalan 4koa, eta depresioaren azpieskalan 3koa.

Bestalde, Euskal Herriko ezaugarri soziolinguistikoak direla-eta, euskarara egokitutako eta baliozkotutako ebaluazio-tresnen beharra agerikoa da. Euskal eremu osoan, 16 urtetik gorako populazioaren $\% 28,4$ euskal hiztuna da, eta \% 16,4 euskaldun hartzailea. Gainera, euskal hiztunen hazkundea adin-talde guztietan gertatu da, 65 urtetik gorako adin-taldean izan ezik. Hala ere, oraindik ere adineko pertsonen \% 20,4 euskal hiztuna da, eta etorkizun hurbilean ehuneko horrek modu esanguratsuan gora egitea aurreikusten da (Eusko Jaurlaritza, Nafarroako Gobernua eta Euskararen Erakunde Publikoa, 2016).

Hartaraz gero, euskarara egokitutako ebaluazio-tresnen beharra azaleratzen da, euskal hiztunen hizkuntza-eskubideei erantzuna emateko asmoz, beste hizkuntza batean komunikatzeko ezgai direlako edota beren ama-hizkuntzan ebaluatuak izatea nahiago dutelako. Euskarazko tresnen garapenak, berebat, euskal hiztunen ebaluazio doiagoa egiteko aukera emango luke.

Beraz, lan honetan, EADGaren euskarazko bertsioaren egokitzapen eta baliozkotzeari gerora bide emango dion ikerketa pilotua gauzatu nahi da. Horretarako, galde-sortaren gaztelaniazko bertsioa hartu da abiapuntutzat, gertutasun geografiko eta soziokulturala direla-eta, zalantza-kasuetan ingelesezko bertsiora jo den arren. Ikerlan honen helburu nagusia euskarazko bertsioaren hasierako fidagarritasuna eta itemen funtzionamendua aztertzea da. Halaber, bigarren helburu bat zehaztu UZTARO 114, 59-78 
da: antsietatearen, depresioaren eta bien arteko komorbilitatearen prebalentziak kalkulatzea, literaturan aurkitu direnekin konparatze aldera. Azkenik, hirugarren helburua, tresnak antsietatearen eta depresioaren azpieskalen artean erlazio esanguratsurik antzematen duen miatzea da, bi nahasmendu horien arteko komorbilitatea dela-eta. Literatura zientifikoan aurkitu denaren bidean, bi azpieskalen artean erlazio positiboa aurkitzea espero da.

\section{Interes zientifiko eta soziala}

Munduko herrialde gehienetan populazioaren zahartzea jazotzen ari da, eta gero eta gehiago dira adin aurreratuenetara heltzen diren adineko pertsonak. Literatura zientifikoari jarraikiz, zahartzaroan arrisku-faktore ezberdinak elkar daitezke, askotariko nahasmendu eta gaixotasunen garapena erraztuz. Nahasmendu emozionalei dagokienez, depresioa eta antsietatea dira adineko pertsonetan ohikoenak; batikbat, egoitzaratutakoadinekoetan. Hartara, aipatutako nahasmenduak pairatzen dituzten edo gara ditzaketen pertsonak antzemateko beharra azaleratzen da. Aitzitik, adineko pertsonei doitutako eta haien dimentsio emozionala neurtzen duten tresnen eskasia agerikoa da. Helburu horrekin erabili izan den galde-sortetako bat Escala de Ansiedad y Depresión de Goldberg (EADG) izan da. Jatorriz populazio horren ebaluaziora bideratu ez zen arren, ezaugarri psikometriko egokiak azaldu ditu hirugarren adinekoen taldean. Gainera, antsietatearen zein depresioaren baheketa egiteko aukera ematen du. Hori bereziki erabilgarria da egoitza-testuinguruetan, non baliabide pertsonalen gabeziak eta denbora-mugapenak nabarmenak diren.

Ikerlan honekin, bestalde, euskarazko ebaluazio-tresnak garatzeko beharrari erantzun nahi zaio hein batean. Izan ere, Euskal Herriko populazioaren kopuru esanguratsu batek bere egunerokotasunean euskara erabiltzen du edo/eta bere ama-hizkuntzatzat jotzen $\mathrm{du}$; are gehiago, euskararen erabilerari dagokionez, azken inkestek goranzko joeraren berri ematen dute. Hala, lurralde honen ezaugarri soziolinguistikoek euskarara egokitutako eta baliozkotutako ebaluazio-tresnen beharra agerian jartzen dute, eta, hartara, EADG galde-sorta euskal hizkuntza eta kulturara egokitu nahi da.

\section{Metodologia}

\subsection{Laginaren deskribapena}

Ikerketa honen itu-populazioa 65 urtetik gorako euskal hiztun egoitzaratuena da. Partaideak egoitzaratutako pertsonak izatea erabaki da, egokitu nahi den tresna egoitza-testuingurutan erabili izan delako adineko pertsonen kasuan. Zehaztutako populazio horretatik, 50 partaideko gutxieneko lagina estimatu zen; izan ere, proba pilotu batean, ordezkatu nahi den populazioko 50-100 parte-hartzaile artean barne hartzea nahikoa litzateke itemen oinarrizko ezaugarri psikometrikoak aztertzeko (Osterlind, 1989). Laginketa ez-probabilistikoa erabili zen; zehazki, nahitako laginketa. Izan ere, euskararen hiru euskalki nagusiak (nafarra, erdialdekoa eta mendebaldekoa) ordezkatzea ahalegindu da, ikerketa Nafarroa eta Gipuzkoako 
eremu soziolinguistiko ezberdinetako zaharren egoitzetan aurrera eramanez; Elizondo, Bera, Zumaia, Zestoa eta Oñati herrietan, hain zuzen.

Ikerketan parte hartzeko, 65 urtetik gorakoak, euskal hiztunak eta egoitzaratuak izateaz gain, parte-hartzaileek honako irizpidea bete behar zuten: narriadura kognitiborik ez izatea. Finean, narriadura kognitiboak itemen ulermen egokia oztopa lezake, eta horregatik, kanporatze-irizpide gisa zehaztu da. Irizpide hori kontrolatzearren, egoitzaratutako partaideen MEC puntuazioa aintzat hartu zen, eta 23 edo gutxiagoko puntuazioa zutenak baztertu ziren. Puntuazio hori egoitzei eskatu zitzaien, erabiltzaileen historia klinikoetan jasotzen den datuetako bat baita.

Behin betiko lagina 68 subjektuk osatu zuten, 66 eta 97 urte bitartean $(\bar{x}=82,71$; DT=7,622). Sexuari dagokionez, gizonezkoak gehiago izan dira (\% 60,3) emakumezkoak baino (\% 39,7). Halaber, ezkongabeak gailendu dira (\% 48,5), alargunen $(\% 32,4)$, ezkonduen $(\% 16,2)$ eta banandu edo dibortziatutakoen $(\% 2,9)$ aurrean.

\subsection{Tresnak}

Parte-hartzaileei aplikatu zitzaien galde-sorta Escala de Ansiedad y Depresión de Goldberg (EADG; Montón et al., 1993) tresnaren euskarazko bertsioa izan zen, Goldberg-en Antsietate eta Depresio Eskala (GADE) izendatua (1. eranskina). Autotxosten heteroaplikatu horrek antsietatearen eta depresioaren baheketa egiteko aukera ematen du, bi nahasmendu horien sintomatologia neurtzen duen azpieskala banaren bitartez.

GADEaren aplikazioa aldagai soziodemografikoei zegozkien galdera batzuekin osatu zen; adinari, sexuari eta egoera zibilari zegozkienak, hain zuzen.

Orobat, galde-sortarekin hasi aurretik, parte-hartzaileei ulertzen ez zuten oro adieraztea eskatu zitzaien, gerta litezkeen ulermen-zailtasunak antzematearren.

\subsection{Prozedura}

Lehenik eta behin, ikerketa aurrera eraman ahal izateko, UPV/EHUko Gizakiekin lotutako Ikerketarako Etika Batzordearen (GIEB) aldeko txostena jaso zen.

Jarraian, tresnaren euskararanzko itzulpena egin zen, gaztelaniako bertsiotik abiatuta. Halere, zalantzak eragin zituzten itemetan, ingelesezko jatorrizko bertsiora jo zen. Itzulpena burutzeko, itzulpen-atzeraitzulpen deritzon prozesuari jarraitu zitzaion. Bi pertsonak itzulpen-proposamen bana egin zuten, eta elkarren artean proposamen bateratu bat adostu. Gero, beste bi kidek atzeraitzulpen-fasean prozedura berari jarraitu zioten, euskarazko proposamen adostutik abiatuta. Azkenean, laurak batu ziren, bertsio originala eta prozesuaren amaierako bertsioa konparatzeko eta euskarazko bertsioaren egokitasuna ebaluatzeko. Azpimarratu nahi da ahalegin berezia egin zela itemen hizkuntza-erregistroa adineko pertsonen mailara egokitzeko (batzuk eskolatuak izan ez diren heinean), bai eta eremu soziolinguistiko ezberdinetan ulerterraza izateko. 
Behin tresna zehaztuta, zaharren egoitzekin harremanetan jarri zen eta beren instalazioetan ikerketa aurrera eramateko baimena eskatu zitzaien. Ondoren, arestian aipatutako barneratze-irizpideak betetzen zituzten parte-hartzaileak biltzeari ekin zitzaion, ikerketaren nondik norakoak azaldu zitzaizkien eta informazio-orri bat eskaini zitzaien. Parte hartzea onartuz gero, partaideek ikerketan parte hartzeko baimen informatu bat sinatu zuten.

Azkenik, parte-hartzaileekin proba aurrera eraman zen, banakako saiotan. Lehenik eta behin, partaideei elkarrizketan zehar suerta zekizkiekeen zalantzak adierazteko eskatu zitzaien. Gero galdera soziodemografikoak egin zitzaizkien, eta segidan, GADEa osorik aplikatu zitzaien; izan ere, ebaluazio psikologikoa gauzatzean lehen lau galderek baheketa bideratzen duten arren, tresnaren egokitzapena burutzean item guztiak ulertzen direla aztertu behar da. Saioek ez zuten iraupen mugaturik, eta elkarrizketatuen beharren arabera aurrera eraman ziren. Hala ere, saio bakoitzak, batez beste, 30 minutu iraun zuen.

\subsection{Datuen analisia}

Datu-analisiaren fasean, analisi kuantitatibo nahiz kualitatiboak egin ziren. Analisi kuantitatiboak egiteko, SPSS softwarearen 23. bertsioa erabili zen. Lehenengo, itemen estatistiko deskribatzaileak (maiztasunak eta portzentajeak, hain zuzen) atera ziren. Bigarren, galde-sortaren barne-trinkotasunaren analisia egin zen, azpieskala bakoitzaren Cronbach-en alfa kalkulatuz. Berebat, azpieskala bakoitzaren itemen funtzionamendua aztertzeko, zuzendutako item-totala korrelazioak atera ziren. Nunnally eta Bernstein-en (1995) irizpideei jarraikiz, azpimarratu nahi da egokitzat jo zirela, batetik, 0,7 eta 0,9 arteko fidagarritasun-koefizienteak (Cronbach-en alfa), eta, bestetik, 0,25-0,30etik gorako zuzendutako item-totala korrelazioak. Hirugarren, bi nahasmenduen eta komorbilitatearen prebalentziak kalkulatu ziren, galdesortaren gaztelaniazko bertsioaren ebaki-puntuen arabera: 4koa antsietatearen azpieskalarako, eta 3koa depresioaren azpieskalarako. Laugarren, antsietatea eta depresioa komorbilitatea aurkezten duten nahasmenduak izanik, bi azpieskalen puntuazioen arteko korrelazio-koefizientea (Spearman-en rho) atera zen.

Bere aldetik, analisi kualitatiboa, partaideek aurkeztu zituzten ulermen-zailtasunen analisiari datxekio. Finean, gaztelaniaz ezagunak eta ulerterrazak suerta daitezkeen termino asko ezezagunak edota korapilatsuak izan litezke euskaraz. Gainera, litekeena zen elkarrizketatuen gehiengoa euskaraz alfabetatua ez izatea, eta ondorioz, ulermen-zailtasun batzuk adieraztea. Hala, ulertezinak ziren edota gaizkiulertuak edo nahasteak eragin zitzaketen termino zein itemak erregistratu ziren.

\section{Emaitzak}

\subsection{Analisi kuantitatiboak}

\subsubsection{Itemen estatistiko deskribatzaileak}

1. eta 2. tauletan biltzen dira, hurrenez hurren, antsietatearen eta depresioaren azpieskaletako itemen maiztasunak eta portzentajeak. 
1. taula. Itemen deskribatzaileak (antsietatearen azpieskala).

\begin{tabular}{|cccccccccccc} 
& & A1 itema & A2 itema & A3 itema & A4 itema & A5 itema & A6 itema & A7 itema & A8 itema & A9 itema \\
$\mathrm{n}(\%)$ & Bai & $17(25)$ & $18(26,5)$ & $7(10,3)$ & $12(17,6)$ & $15(22,1)$ & $10(14,7)$ & $10(14,7)$ & $14(20,6)$ & $17(25)$ \\
& Ez & $51(75)$ & $50(73,5)$ & $61(89,7)$ & $56(82,4)$ & $53(77,9)$ & $58(85,3)$ & $58(85,3)$ & $54(79,4)$ & $51(75)$
\end{tabular}

1. taulari erreparatuta, antsietatearen azpieskalako itemei baiezko erantzuna eman dietenen portzentajeak txikiak dira, \% 10,3 eta \% 26,5 artean daude. Portzentaje txikiena A3 itemari dagokio, eta handiena, berriz, A2 itemari.

\section{2. taula. Itemen deskribatzaileak (depresioaren azpieskala).}

\begin{tabular}{|rrrrrrrrrrr} 
& & D1 itema & D2 itema & D3 itema & D4 itema & D5 itema & D6 itema & D7 itema & D8 itema & D9 itema \\
$\mathrm{n}(\%)$ & Bai & $18(26,5)$ & $6(8,8)$ & $7(10,3)$ & $7(10,3)$ & $11(16,2)$ & $4(5,9)$ & $10(14,7)$ & $16(23,5)$ & $4(5,9)$ \\
& Ez & $50(73,5)$ & $62(91,2)$ & $61(89,7)$ & $61(89,7)$ & $57(83,8)$ & $64(94,1)$ & $58(85,3)$ & $52(76,5)$ & $64(94,1)$
\end{tabular}

2. taulan ikus daitekeenez, depresioaren azpieskalan sintomak agertzen dituztenen portzentajeak ere txikiak dira: \% 5,9 eta \% 26,5 artean daude. Balio txikiena D6 eta D9 itemei dagokie, eta handiena, aldiz, D1 itemari.

\subsubsection{Fidagarritasuna}

Antsietatearen azpieskalaren kasuan, fidagarritasun-analisiaren emaitzak adierazten du azpieskala honen fidagarritasuna egokia dela (Cronbach-en alfa $=0,74$ ). Itemen funtzionamenduari dagokionez, zuzendutako item-totala korrelazioak 3. taulan jasotzen dira.

3. taula. Zuzendutako item-totala korrelazioak (antsietatearen azpieskala).

A1 itema A2 itema A3 itema A4 itema A5 itema A6 itema A7 itema A8 itema A9 itema

\begin{tabular}{llllllllll}
\hline $\begin{array}{l}\text { Zuzendutako } \\
\text { item-totala } \\
\text { korrelazioa }\end{array}$ & 0,46 & 0,47 & 0,37 & 0,49 & 0,52 & 0,35 & 0,42 & 0,30 & 0,40 \\
\hline
\end{tabular}

Korrelazioak 0,30 eta 0,52 balioen artean kokatzen dira. Balio txikiena $A 8$ itemari dagokio, eta handiena, berriz, A5 itemari.

Depresioaren azpieskalaren kasuan, fidagarritasun-analisiak azpieskalaren fidagarritasuna egokia dela azaldu du (Cronbach-en alfa $=0,78$ ). Bestalde, itemen funtzionamenduaren berri ematen duten korrelazioak 4. taulan jasotzen dira. 
4. taula. Zuzendutako item-totala korrelazioak (depresioaren azpieskala).

D1 itema D2 itema D3 itema D4 itema D5 itema D6 itema D7 itema D8 itema D9 itema

Zuzendutako

item-totala

0,61

$0,51 \quad 0,44$

0,54

0,48

0,19

0,49

0,62

0,30

Emaitzei erreparatuta, korrelazioak 0,19 eta 0,62 balioen artean daude. Balio txikiena D6 itemari dagokio, eta handiena, ordea, D8 itemari. D6 itemaren korrelazioa txikia da, eta ez du egokitasunerako zehaztutako irizpidea betetzen.

\subsubsection{Antsietatearen eta depresioaren prebalentziak}

Aztertutako laginean antsietatearen prebalentzia \% 23,5ekoa izan da eta depresioarena \% 25ekoa. Komorbilitateari dagokionez, \% 13,2k bi nahasmenduak aldi berean azaldu ditu.

\subsubsection{Antsietatearen eta depresioaren azpieskalen arteko korrelazioa}

Antsietatearen eta depresioaren azpieskalen arteko erlazioa estatistikoki esanguratsua da $(p=0,01)$. Antzemandako efektuaren tamaina ertaina da $(r=0,47)$, eta bi azpieskalen arteko korrelazioa positiboa da.

\subsection{Analisi kualitatiboak}

Analisi kuantitatiboez landa, elkarrizketetan adineko pertsonek azaldu dituzten ulermen-zailtasunak ere ikertu dira. Parte-hartzaile gehienek galde-sorta ia osotasunean ulertu duten arren, zalantzak eragin dituzten zenbait hitz egon dira. A8 itemeko «inurridurak» eta D4 itemeko «etsita» hitzak izan dira, batez ere, ulertu ez direnak. Maila txikiagoan, «haserrekor», «zailtasun», «gauzekiko» eta «buruarekiko» hitzek zalantza bat edo beste eragin dute. Azkenik, D5 itemak partaideak ezbaian utzi ditu kasu gutxi batzuetan.

\section{Eztabaida}

Lan honetan, funtsean, EADG galde-sorta euskarara egokitu eta hasierako analisiak egin nahi ziren, adineko pertsona egoitzaratuen populazioarekin. Ildo horretatik, helburu nagusia, euskarazko bertsioaren fidagarritasuna eta itemen hasierako funtzionamendua aztertzea zen. Bertsioaren egokitasuna probatzeko, zehazki, analisi kuantitatiboak zein kualitatiboak gauzatu dira.

Analisi kuantitatiboei dagokienez, batetik, baiezko erantzunen maiztasuna txikia izan da ezezko erantzunekin erkatuta. Horren zergatia ikerketa lagin ezklinikoarekin aurrera eramateari letxekioke. Itemek, halaber, aldakortasun egokia azaldu dute. Bestetik, azpieskala bakoitzaren barne-trinkotasunaren analisia egin da eta antsietatearen nahiz depresioaren azpieskalek fidagarritasun-maila egokia agertu dute. Orobat, zuzendutako item-totala korrelazioak ere egokiak suertatu dira orokorrean. Haatik, D6 itemak puntuazio baxua azaldu du. Emaitza horren zergatiak itemaren lehenengo zatiarekin («Pisurik galdu al duzu...?») zerikusia duela uste 
da. Lehenengo zati hori bigarren zatiari («...apetitu faltaren ondorioz?») gailenduko litzaioke, eta horrek arazoak ekar litzake. Izan ere, egoitzaratutako pertsonek askotan ez dakite pisurik galdu ote duten; eta gainera, pisua modu esanguratsuan galdu ez dutela pentsa dezakete edota apetitu falta izan dezakete pisua galdu dutela ohartu gabe. Itemak emaitza egokia azaldu ez badu ere, esangura teoriko nabarmena dauka neurtzen duen konstruktuari (depresioa) begira; hortaz, itema birformulatzea proposatzen da, lehenengo zatia ezabatuz eta bigarrena moldatuz.

Analisi kualitatiboak, bere aldetik, hainbat ulermen-zailtasun mahaigaineratu ditu, eta horiek saihesteko zenbait proposamen egingo dira hurrengo lerroetan. Pertsona batzuek ez dute «inurridurak» (A8) terminoa ulertu; aitzitik, partaideei berorren esanahia azaltzean, gehienek «txingurridura» hitza erabiltzen dutela adierazi dute, eta hartara, hitz horrekin ordezkatzea komenigarria begiesten da. «Etsita» (D4) hitzak ere arazoak ekarri ditu zenbait kasutan, eta ondorioz, hori ezabatzea proposatzen da, itemaren ulermenerako erabakigarria ez den heinean.

Arestian aipatu legez, «haserrekor», «zailtasun», «gauzekiko» eta «buruarekiko» hitzek behin edo behin zalantzak eragin dituzte. «Haserrekor» (irascible, gaztelaniaz) terminoari dagokionez, gehienetan ulertu den arren, «-kor» atzizkia kentzea iradokitzen da; izan ere, antzeman da atzizki horrek ez duela gaztelaniazko terminoaren konnotazioa eragiten, eta beraz, nahasmendurik sortuko ez duen «haserre» hitza erabiltzeari egokiagoa iritzi zaio. Bestalde, "gauzekiko» (D2) eta «buruarekiko» (D3) hitzen «-ekiko» amaierak hainbat partaide nahastu ditu, eta horregatik, "gauzengatik» eta «buruan» hitzekin ordezkatzea proposatzen da, hurrenez hurren, itemen ulermena erraztuko dutelakoan. Halaber, «zailtasun» hitzaren kasuan, «arazo» hitzarekin ordezkatzea iradokitzen da, arrazoi beragatik. Horiez gain, D5 itema bere osotasunean ulertzeko zailtasunak igarri dira zenbait partaidetan; izan ere, gehienek galdera zehaztea eskatzen zuten. Hori adierazpenaren zehaztugabetasunagatik dela uste da. Hala ere, itema ez birformulatzea planteatzen da, zehaztugabetasun hori beharrezkotzat jotzen baita aztertu nahi den sintoma ondo neurtzeko. Azken batean, sintoma depresibo zein antsiosoak adierazpen subjektiboak dira (Fernández-Ballesteros et al., 1991; Franco, Orihuela eta Sanguino, 1996), eta itemen zehaztugabetasunak parte-hartzailearen subjektibotasuna eragitea erraz lezake.

Zerrendatu diren ulermen-zailtasun edo zalantzak aintzat hartu dira GADEaren bertsio hobe bat proposatze aldera (2. eranskina); are gehiago, egindako aldaketak beharrezkoak ikusten dira GADEaren egokitzapenaren fase esperimentalari ekiteko.

Puntu honetan, azpimarratu nahi da beren egunerokotasunean euskara erabiltzen duten arren, adineko pertsona asko hizkuntza horretan letragabeak direla, gaztelaniaz ikasi behar izan baitzuten. Gainera, pertsona horiek tokian tokiko euskaraz mintzatzen dira. Bi arrazoi horiek direla-eta, pertsona horiek euskara batuan garatutako galde-sorta honen aurrean ulermen-zailtasunak adieraztea ulergarria da. Hala eta guztiz ere, orokorrean, partaideek itemekiko ulermen ona azaldu dute, besteak beste, itemen hizkuntza-erregistroa bereziki zaindu baita hizpide den populazioari begira, bai eta eremu soziolinguistiko ezberdinetan ulerterraza izate aldera ere. 
Ikerketa pilotu honen bigarren helburua, antsietatearen, depresioaren eta bien arteko komorbilitatearen prebalentzien kalkuluari zegokion. Aurkitutako prebalentziek bat egiten dute adineko pertsona egoitzaratuen osasun mentala aztertu duten ikerketen emaitzekin, antsietatearen kasuan (Bryant et al., 2008), depresioaren kasuan (Azeem eta Naz, 2015; Franco eta Monforte, 1996), bai eta komorbilitatearen kasuan ere (Suradom et al., 2019; van Balkom et al., 2000). Komorbilitatearekin lotuta, ikerlan honen hirugarren helburua izan da miatzea ea GADEak antsietatearen eta depresioaren artean erlazio esanguratsurik antzematen duen. Analisiek bi aldagaien arteko korrelazio positiboa aurkitu dute, literatura zientifikoan aurkitutako emaitzen bidean (adib., Almeida et al., 2012; Beekman et al., 2000; Suradom et al., 2019). Lortutako emaitza horrek antsietatearen eta depresioaren arteko komorbilitatea azpimarratzen du. Azken batean, zahartzaroan askotariko arrisku-faktoreak elkar daitezke (besteak beste, alarguntzea, sare soziala murriztea, osasun-arazoak agertzea, narriadura kognitiboa hastea eta egoitzaratzea), eta horiek berebiziko eragina izan dezakete nahasmendu emozionalen garapenean. Gainera, depresioak eta antsietateak, nahasmendu ezberdinak izan arren, antzeko arrisku-faktoreak izan litzakete, eta, horrek, nahasmenduen aldiberekotasuna azal lezake.

Arestian emaitzen egokitasuna nabarmendu bada ere, ikerketa honen zenbait muga aipatu behar dira. Batetik, ikerketa pilotu batean ohikoa den legez, laginaren tamaina txiki samarra izan da, eta ondorioz, emaitzak tentuz interpretatu beharrekoak dira. Hala, emaitza hauek GADE galde-sorta fidagarria izan daitekeela iradokitzen duten arren, fase esperimentalari ekin beharko litzaioke zantzu hori berretsi ahal izateko. Bestetik, lagina, adineko pertsona egoitzaratuek osatu dute, eta hortaz, tresna honek adinekoen populazio orokorrean izan dezakeen egokitasuna ezbaian legoke. Azkenik, euskarari dagokionez, beronen hiru euskalki nagusiak ordezkatzea ahalegindu bada ere, egia da euskalki bakoitzaren baitan beste hainbeste aldaera aurki daitezkeela, eta hartara, horiek ere laginketa esperimentalean barne hartu beharko lirateke euskarazko egokitzapen xehea gauzatzearren.

\section{Ondorioak}

Ikerlan honetan EADGaren euskararanzko egokitzapenaren ikerketa pilotua aurrera eraman da adineko pertsona egoitzaratuekin, eta halaber, galde-sortaren hasierako oinarrizko ezaugarri psikometrikoen berri eman da. Galde-sortak azaldu duen barne-trinkotasun mailak GADEa eskala fidagarria izan daitekeela iradokitzen du. Finean, tresna honek, egokitzapen osoa gauzatzean, adineko euskal hiztun egoitzaratuetan antsietatearen eta depresioaren baheketa egiteko aukera eman nahi luke, aplikazio azkar eta erraz baten bitartez. Horrek berebiziko garrantzia hartzen du, batez ere, gero eta adineko pertsona eta euskal hiztun gehiago dituen Euskal Herrian. Hala, GADEak, euskaldunen hizkuntza-eskubideei erantzuteaz gain, aipatutako nahasmenduak pairatzen dituzten edo gara ditzaketen adineko pertsonak antzemateko erabilgarria izatea du helburu; gerora, haiekin esku hartzeko, haien ongizatea eta integritatea zaintze eta ziurtatze aldera. 


\section{Eskertzak}

Gure eskerrik beroenak helarazi nahi genizkieke Berako San José, Elizondoko Francisco Joaquín Iriarte, Oñatiko San Martín, Zestoako San Juan eta Zumaiako Otezuri egoitzetako parte-hartzaile eta langileei, ikerlan hau aurrera eramateko eskainitako laguntzagatik.

\section{Bibliografia}

Abellán, A.; Aceituno, P.; Pérez, J.; Ramiro, D.; Ayala, A. eta Pujol, R. (2019): Un perfil de las personas mayores en España, 2019: Indicadores estadísticos básicos, <http:// envejecimiento.csic.es/documentos/documentos/enred-indicadoresbasicos2019. pdf> (Kontsulta: 2019-03-14).

Agulló, M.S. (2001): Mayores, actividad y trabajo en el proceso de envejecimiento y jubilación: Una aproximación psico-sociológica, IMSERSO, Madril.

Almeida, O.P.; Draper, B.; Pirkis, J.; Snowdon, J.; Lautenschlager, N.T.; Byrne, G.; ... Pfaff, J.J. (2012): «Anxiety, depression, and comorbid anxiety and depression: Risk factors and outcome over two years», International Psychogeriatrics, 24, 1.6221.632.

Álvarez-Hernández, J. eta Sicilia, M. (2007): «Deterioro cognitivo y autonomía personal básica en personas mayores», Anales de Psicología, 23, 272-281.

Andreas, S.; Schulz, H.; Volkert, J.; Dehoust, M.; Sehner, S.; Suling, A.; ... Härter, M. (2017): «Prevalence of mental disorders in elderly people: The European MentDis_ICF65+ study», British Journal of Psychiatry, 210, 125-131.

Antón, M.; Gálvez, N. eta Esteban, R. (2006): «Depresión y ansiedad», in Sociedad Española de Geriatría y Gerontología (arg.), Tratado de geriatría para residentes, Sociedad Española de Geriatría y Gerontología, Madril, 243-249.

Azeem, F. eta Naz, M.A. (2015): «Resilience, death anxiety, and depressión among institutionalized and noninstitutionalized elderly », Pakistan Journal of Psychological Research, 30, 111-130.

Beck, A.T.; Epstein, N.; Brown, G. eta Steer, R.A. (1988): «An inventory for measuring clinical anxiety: Psychometric properties», Journal of Consulting and Clinical Psychology, 56, 893-897.

Beck, A.T.; Ward, C.H.; Mendelson, M.; Mock, J. eta Erbaugh, J. (1961): «An inventory for measuring depression», Archives of General Psychiatry, 4, 561-571.

Beekman, A.T.F.; de Beurs, E.; van Balkom, A.J.L.M.; Deeg, D.J.H.; van Dyck, R. eta van Tilburg, W. (2000): «Anxiety and depression in later life: Co-occurrence and communality of risk factors», American Journal of Psychiatry, 157, 89-95.

Blazer, D.; Burchett, B.; Service, C. eta George, L.K. (1991): «The association of age and depression among the elderly: An epidemiologic exploration», Journal of Gerontology, 46, M210-M215.

Brink, T.L.; Yesavage, J.A.; Lum, O.; Heersema, P.; Adey, M. eta Rose, T.L. (1982): «Screening tests for geriatric depression», Clinical Gerontologist, 1, 37-44.

Bryant, C.; Jackson, H. eta Ames, D. (2008): «The prevalence of anxiety in older adults: Methodological issues and a review of the literature», Journal of Affective Disorders, 109, 233-250.

Buber, I. eta Engelhardt, H. (2011): «The association between age and depressive symptoms among older men and women in Europe: Findings from SHARE», Comparative Population Studies, 36, 103-126. 
Calvo-Soto, A.P. eta Gómez-Ramírez, E. (2018): «Condiciones de salud y factores relacionados con discapacidad en adultos mayores: Una reflexión para la atención", Universidad y Salud, 20, 270-282.

Cisneros, G.E. eta Ausín, B. (2019): «Prevalencia de los trastornos de ansiedad en las personas mayores de 65 años: Una revisión sistemática», Revista Española de Geriatría y Gerontología, 54, 34-48.

Damián, J.; Pastor-Barriuso, R. eta Valderrama-Gama, E. (2010): «Descriptive epidemiology of undetected depression in institutionalized older people», Journal of the American Medical Directors Association, 11, 312-319.

Escobar, M.Á.; Botigué, T.; Jürschik, P.; Nuin, C. eta Blanco, J. (2013): «Sintomatología depresiva en ancianos: Influencia de género», Revista Española de Geriatría y Gerontología, 48, 59-64.

Euskal Estatistika Erakundea (2017): Piramide interaktiboak [Datu-basea], <http://eu.eustat. eus/indic/indicadoresgraficosvista. aspx?idgraf $=11680 \&$ opt=1\&tema=268> (Kontsulta: 2019-03-10).

Eusko Jaurlaritza, Nafarroako Gobernua eta Euskararen Erakunde Publikoa (2016): VI. inkesta soziolinguistikoa: Euskararen eremu osoa, <http://eu.eustat.eus/estadisticas/ tema_460/opt_0/tipo_3/ti_Euskararen_erabilera/temas.html> (Kontsulta: 201903-29).

Fernández-Alonso, M.C.; Buitrago, F.; Ciurana, R.; Chocrón, L.; García-Campayo, J.; Montón, C.; ... Tizón, J. (2007): «Programa de prevención en salud mental en atención primaria», Atención Primaria, 39, 88-108.

Fernández-Ballesteros, R.; Izal, M.; Montorio, I.; González, J.L. eta Díaz, P. (1991): Evaluación e intervención psicológica en la vejez, Martínez-Roca, Madril.

Fernández-Fernández, C.; Caballer, J.; Sáiz, P. A.; García-Portilla, M.P.; Martínez, S. eta Bobes, J. (2006): «Depression in the elderly living in a rural area and other related factors», Actas Españolas de Psiquiatría, 34, 355-361.

Folstein, M.F.; Folstein, S.E. eta McHugh, P.R. (1975): «Mini-Mental State: A practical method for granding the cognitive state of patients for the clinical», Journal of Psychiatric Research, 12, 189-198.

Franco, M.Á. eta Monforte, J.A. (1996): «¿Cuál es la frecuencia de la depresión en el anciano?», in A. Calcedo (arg.), La depresión en el anciano: Doce cuestiones fundamentales, Fundación Archivos de Neurobiología, Madril, 19-43.

Franco, M.Á.; Orihuela, T. eta Sanguino, R. (1996): «¿Qué utilidad tienen los instrumentos de valoración de la depresión en el anciano? », in A. Calcedo (arg.), La depresión en el anciano: Doce cuestiones fundamentales, Fundación Archivos de Neurobiología, Madril, 125-154.

Gaindegia (2015): Euskal Herriak 85 urtetik gorako biztanle gehiago izango ditu, hamar urtetik beherakoak baino [Web blog posta], <https://www.gaindegia.eus/eu/azpimarrabiztanleria-zahartzea> (Kontsulta: 2019-03-10).

Gallagher, D. eta Thompson, L.W. (1983): «Depression», in P.M. Lewinshon eta L. Teri (arg.), Clinical geropsychology: New directions in assessment and treatment, Pergamon Press, New York, 7-37.

Goldberg, D.; Bridges, K.; Duncan-Jones, P. eta Grayson, D. (1988): «Detecting anxiety and depression in general medical settings», British Medical Journal, 297, 897-899.

Grenier, S.; Payette, M.C.; Gunther, B.; Askari, S.; Desjardins, F.F.; Raymond, B. eta Berbiche, D. (2019): «Association of age and gender with anxiety disorders in older adults: A systematic review and meta-analysis», International Journal of Geriatric Psychiatry, 34, 397-407. 
Íñiguez, J. (2009): «Evaluación e intervención psicogerontológica de los trastornos depresivos», in R. Fernandez-Ballesteros (arg.), Psicología de la vejez: Una psicogerontología aplicada, Pirámide, Madril, 137-156.

Koloski, N.A.; Smith, N.; Pachana, N.A. eta Dobson, A. (2008): «Performance of the Goldberg Anxiety and Depression Scale in older women», Age and Ageing, 37, 464-467.

Leturia, F.J.; Yanguas, J.J.; Arriola, E. eta Uriarte, A. (2001): La valoración de las personas mayores: evaluar para conocer, conocer para intervenir, Cáritas Española, Madril.

Lobo, A.; Ezquerra, J.; Gómez-Burgada, F.; Sala, J.M. eta Seva, A. (1979): «El Mini-Examen Cognoscitivo: Un test sencillo, práctico, para detectar alteraciones intelectuales en pacientes médicos", Actas Luso-Españolas de Neurología, Psiquiatría y Ciencias Afines, 7, 189-202.

López, Á.G. eta Calero, M.D. (2009): «Predictores del deterioro cognitivo en ancianos», Revista Española de Geriatría y Gerontología, 44, 220-224.

Lowe, P.A. eta Reynolds, C.R. (2005): «Do relationships exist between age, gender and education and self-reports of anxiety among older adults? », Individual Differences Research, 3, 239-259.

Mackinnon, A.; Christensen, H.; Jorm, A. F.; Henderson, A.S.; Scott, R. eta Korten, A.E. (1994): «A latent trait analysis of an inventory designed to detect symptoms of anxiety and depression using an elderly community sample», Psychological Medicine, 24, 977-986.

Molina-Linde, J.M.; Sánchez-Hernández, M.P.; Rubio, R. eta Uribe, A.F. (2005): «Diferencias en la calidad de vida y estado anímico de pacientes mayores hospitalizados según el género», Pensamiento Psicológico, 1, 17-26.

Montón, C.; Pérez-Echeverría, M.J.; Campos, R.; García-Campayo, J.; Lobo, A. eta GMPPZ (1993): «Escalas de ansiedad y depresión de Goldberg: Una guía de entrevista eficaz para la detección del malestar psíquico», Atención Primaria, 12, 345-349.

Montorio, I. (1994): La persona mayor: Guía aplicada de evaluación psicológica, INSERSO, Madril.

Montorio, I.; Nuevo, R.; Losada, A. eta Márquez, M. (2001): «Prevalencia de trastornos de ansiedad y depresión en una muestra de personas mayores residentes en la comunidad», Mapfre Medicina, 12, 19-26.

Nafarroako Estatistika Erakundea (2019): Populazio adierazleak [Datu-basea], <https://administracionelectronica.navarra.es/GN.InstitutoEstadistica.Web/ informacionestadistica.aspx?R=1\&E=1> (Kontsulta: 2019-03-10).

Nafarroako Gobernua (2017): Zahartze aktibo eta osasungarrirako Nafarroako estrategia 2017-2022, Nafarroako Osasun Publikoaren eta Lan Osasunaren Institutua, Iruñea.

Norton, J.; Ancelin, M.L.; Stewart, R.; Berr, C.; Ritchie, K. eta Carrière, I. (2012): «Anxiety symptoms and disorder predict activity limitations in the elderly», Journal of Affective Disorders, 141, 276-285.

Nunnally, J.C. eta Bernstein, I.H. (1995): Teoría psicométrica [3. arg.], McGraw-Hill, Mexiko.

Osasunaren Munduko Erakundea (2011): World report on disability, <https://www.who.int/ disabilities/world_report/2011/en/> (Kontsulta: 2019-03-24).

(2015): World report on ageing and health, <https://www.who.int/ageing/ publications/world-report-2015/en/> (Kontsulta: 2019-03-24).

Osterlind, S.J. (1989): Constructing test items, Kluwer Academic Publishers, Dordrecht.

Osterrieth, P. (1944): «Le test de copie d une figure complexe: Contribution à I étude de la perception et de la memoire», Archives de Psychologie, 30, 206-356. 
Pachana, N.A.; Byrne, G.J.; Siddle, H.; Koloski, N.; Harley, E. eta Arnold, E. (2007): «Development and validation of the Geriatric Anxiety Inventory», International Psychogeriatrics, 19, 103-114.

Rey, A. (1941): "L'examen psychologique dans les cas d'encephalopathie traumatique», Archives de Psychologie, 28, 286-340.

Sarró, M.; Ferrer, A.; Rando, Y.; Formiga, F. eta Rojas, S. (2013): «Depresión en ancianos: Prevalencia y factores asociados", Semergen, 39, 354-360.

Segal, D.L.; June, A.; Payne, M.; Coolidge, F.L. eta Yochim, B. (2010): «Development and initial validation of a self-report assessment tool for anxiety among older adults: The Geriatric Anxiety Scale», Journal of Anxiety Disorders, 24, 709-714.

Sendra, J.M.; Asensio, I. eta Vargas, M.L. (2017): «Características y factores asociados a la depresión en el anciano en España desde una perspectiva de género», Actas Españolas de Psiquiatría, 45, 185-200.

Sheikh, J.I. (1996): «Anxiety disorders», in J. Sadovoy; L.L. Lazarus; L.F. Jarvik eta T. Grossberg (arg.), Comprehensive review of geriatric psychiatry [2. arg], American Psychiatric Press, Washington, 369-386.

Stordal, E.; Krüger, M.B.; Dahl, N.H.; Krüger, Ø.; Mykletun, A. eta Dahl, A.A. (2001): «Depression in relation to age and gender in the general population: The NordTrødelag Health Study (HUNT) », Acta Psychiatrica Scandinavica, 104, 361-370.

Stordal, E.; Mykletun, A. eta Dahl, A.A. (2003): «The association between age and depression in the general population: A multivariate examination», Acta Psychiatrica Scandinavica, 107, 132-141.

Suradom, C.; Wongpakaran, N.; Wongpakaran, T.; Lerttrakarnoon, P.; Jiraniramai, S.; Taemeeyapradit, U.; ... Arunpongpaisal, S. (2019): «Prevalence and associated factors of comorbid anxiety disorders in late-life depression: Findings from geriatric tertiary outpatient settings", Neuropsychiatric Disease and Treatment, 15, 199204.

van Balkom, A.J.L.M.; Beekman, A.T.F.; de Beurs, E.; Deeg, D.J.H.; van Dyck, R. eta van Tilburg, W. (2000): «Comorbidity of the anxiety disorders in a community-based older population in The Netherlands», Acta Psychiatrica Scandinavica, 101, 3745.

Vink, D.; Aartsen, M.J. eta Schoevers, R.A. (2008): «Risk factors for anxiety and depression in the elderly: A review», Journal of Affective Disorders, 106, 29-44.

Vinuesa, J. eta Moreno, A. (2000): «Sociodemografía», in R. Fernández-Ballesteros (arg.), Gerontología social, Pirámide, Madril, 55-78.

Volkert, J.; Härter, M.; Dehoust, M.C.; Ausín, B.; Canuto, A.; Da Ronch, C.; ... Andreas, S. (2017): «The role of meaning in life in community-dwelling older adults with depression and relationship to other risk factors", Aging and Mental Health, 23, 100-106.

Wechler, D. (1945): "A standardized memory scale for clinical use», The Journal of Psychology: Interdisciplinary and Applied, 19, 87-95.

Wild, B.; Herzog, W.; Schellberg, D.; Lechner, S.; Niehoff, D.; Brenner, H.; ... Raum, E. (2012): «Association between the prevalence of depression and age in a large representative German sample of people aged 53 to 80 years», International Journal of Geriatric Psychiatry, 27, 375-381.

Wolitzky-Taylor, K.B.; Castriotta, N.; Lenze, E. J.; Stanley, M.A. eta Craske, M.G. (2010): "Anxiety disorders in older adults: A comprehensive review», Depression and Anxiety, 27, 190-211. 
Yaka, E.; Keskinoglu, P.; Ucku, R.; Yener, G.G. eta Tunca, Z. (2014): «Prevalence and risk factors of depression among community dwelling elderly », Archives of Gerontology and Geriatrics, 59, 150-154.

Yesavage, J.A.; Brink, T.L.; Rose, T.L.; Lum, O.; Huang, V.; Adey, M. eta Leirer, V.O. (1983): «Development and validation of a geriatric depression screening scale: $A$ preliminary report», Journal of Psychiatric Research, 17, 37-49.

Zigmond, A.S. eta Snaith, R.P. (1983): «The Hospital Anxiety and Depression Scale», Acta Psychiatrica Scandinavica, 67, 361-370.

Zung, W.W. (1965): «A self-rating depression scale», Archives of General Psychiatry, 12, 63-70. 


\section{Eranskinak}

\section{1. eranskina: Goldberg-en Antsietate eta Depresio Eskala (GADE) - Hasierako bertsioa}

Azken bi asteetan:

\begin{tabular}{|c|c|c|}
\hline \multicolumn{3}{|c|}{ ANTSIETATEAREN AZPIESKALA } \\
\hline 1 & Urduri edo tentsioan egon al zara? & $\mathrm{BAI} / \mathrm{EZ}$ \\
\hline 2 & Zerbaitek asko kezkatu al zaitu? & $\mathrm{BAI} / \mathrm{EZ}$ \\
\hline 3 & Oso haserrekor sentitu al zara? & $\mathrm{BAI} / \mathrm{EZ}$ \\
\hline 4 & Lasaitzeko zailtasunik izan al duzu? & $\mathrm{BAI} / \mathrm{EZ}$ \\
\hline \multicolumn{3}{|c|}{ Bi edo gehiagotan baiezkoa emanez gero, galdetzen jarraitu } \\
\hline 5 & Gaizki lo egin al duzu, lo egiteko zailtasunak izan al dituzu? & $\mathrm{BAI} / \mathrm{EZ}$ \\
\hline 6 & Buruko edo lepoko minik izan al duzu? & $\mathrm{BAI} / \mathrm{EZ}$ \\
\hline 7 & $\begin{array}{l}\text { Hurrengo sintomarik izan al duzu: dardarak, } \\
\text { inurridurak, zorabioak, izerdiak, beherakoa? }\end{array}$ & $\mathrm{BAI} / \mathrm{EZ}$ \\
\hline 8 & Zure osasunak kezkatu al zaitu? & $\mathrm{BAI} / \mathrm{EZ}$ \\
\hline 9 & Lo hartzeko zailtasunik izan al duzu? & $\mathrm{BAI} / \mathrm{EZ}$ \\
\hline \multicolumn{3}{|c|}{ DEPRESIOAREN AZPIESKALA } \\
\hline 1 & Energia gutxirekin sentitu al zara? & $\mathrm{BAI} / \mathrm{EZ}$ \\
\hline 2 & Gauzekiko interesa galdu al duzu? & $\mathrm{BAI} / \mathrm{EZ}$ \\
\hline 3 & Zure buruarekiko konfiantza galdu al duzu? & $\mathrm{BAI} / \mathrm{EZ}$ \\
\hline 4 & Etsita, esperantzarik gabe sentitu al zara? & $\mathrm{BAI} / \mathrm{EZ}$ \\
\hline \multicolumn{3}{|c|}{ Baiezko bat egonez gero, galdetzen jarraitu } \\
\hline 5 & Kontzentratzeko zailtasunik izan al duzu? & $\mathrm{BAI} / \mathrm{EZ}$ \\
\hline 6 & Pisurik galdu al duzu (apetitu faltaren ondorioz)? & $\mathrm{BAI} / \mathrm{EZ}$ \\
\hline 7 & Goizegi esnatzen ibili al zara? & $\mathrm{BAI} / \mathrm{EZ}$ \\
\hline 8 & Motel sentitu al zara? & $\mathrm{BAI} / \mathrm{EZ}$ \\
\hline 9 & Zure ustez, goizetan okerrago sentitu izan zara? & $\mathrm{BAI} / \mathrm{EZ}$ \\
\hline
\end{tabular}




\section{2. eranskina: Goldberg-en Antsietate eta Depresio Eskala (GADE) - Ikerketa pilotutik eratorritako bertsioa}

Azken bi asteetan:

\begin{tabular}{|c|c|c|}
\hline \multicolumn{3}{|c|}{ ANTSIETATEAREN AZPIESKALA } \\
\hline 1 & Urduri edo tentsioan egon al zara? & $\mathrm{BAI} / \mathrm{EZ}$ \\
\hline 2 & Zerbaitek asko kezkatu al zaitu? & $\mathrm{BAI} / \mathrm{EZ}$ \\
\hline 3 & Oso haserre sentitu al zara? & $\mathrm{BAI} / \mathrm{EZ}$ \\
\hline 4 & Lasaitzeko arazorik izan al duzu? & $\mathrm{BAI} / \mathrm{EZ}$ \\
\hline \multicolumn{3}{|c|}{ Bi edo gehiagotan baiezkoa emanez gero, galdetzen jarraitu } \\
\hline 5 & Gaizki lo egin al duzu, lo egiteko arazoak izan al dituzu? & $\mathrm{BAI} / \mathrm{EZ}$ \\
\hline 6 & Buruko edo lepoko minik izan al duzu? & $\mathrm{BAI} / \mathrm{EZ}$ \\
\hline 7 & $\begin{array}{l}\text { Hurrengo sintomarik izan al duzu: dardarak, } \\
\text { txingurridurak, zorabioak, izerdiak, beherakoa? }\end{array}$ & $\mathrm{BAI} / \mathrm{EZ}$ \\
\hline 8 & Zure osasunak kezkatu al zaitu? & $\mathrm{BAI} / \mathrm{EZ}$ \\
\hline 9 & Lo hartzeko arazoak izan al dituzu? & $\mathrm{BAI} / \mathrm{EZ}$ \\
\hline \multicolumn{3}{|c|}{ DEPRESIOAREN AZPIESKALA } \\
\hline 1 & Energia gutxirekin sentitu al zara? & $\mathrm{BAI} / \mathrm{EZ}$ \\
\hline 2 & Gauzengatik zenuen interesa galdu al duzu? & $\mathrm{BAI} / \mathrm{EZ}$ \\
\hline 3 & Zure buruan konfiantza galdu al duzu? & $\mathrm{BAI} / \mathrm{EZ}$ \\
\hline 4 & Esperantzarik gabe sentitu al zara? & $\mathrm{BAI} / \mathrm{EZ}$ \\
\hline \multicolumn{3}{|c|}{ Baiezko bat egonez gero, galdetzen jarraitu } \\
\hline 5 & Kontzentratzeko arazoak izan al dituzu? & $\mathrm{BAI} / \mathrm{EZ}$ \\
\hline 6 & Apetitu falta izan al duzu? & $\mathrm{BAI} / \mathrm{EZ}$ \\
\hline 7 & Goizegi esnatzen ibili al zara? & $\mathrm{BAI} / \mathrm{EZ}$ \\
\hline 8 & Motel sentitu al zara? & $\mathrm{BAI} / \mathrm{EZ}$ \\
\hline 9 & Zure ustez, goizetan okerrago sentitu izan zara? & $\mathrm{BAI} / \mathrm{EZ}$ \\
\hline
\end{tabular}



